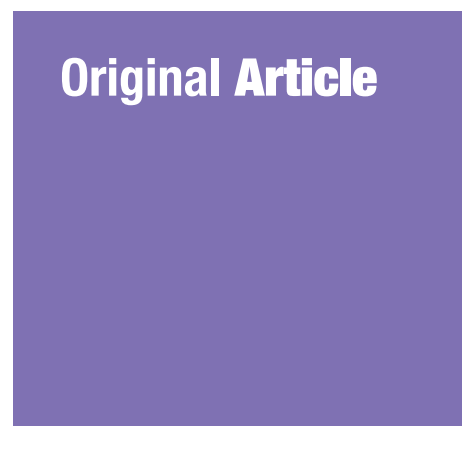

Submitted: 30 Jun 2019 Accepted: 12 Feb 2020 Online: 30 Apr 2020

\section{Reliability and Validity of the Osteoarthritis Research Society International Minimal Core Set of Recommended Performance- Based Tests of Physical Function in Knee Osteoarthritis in Community-Dwelling Adults}

\author{
Ariyachaikul Suwit, Kanthain Rungtiwa, Thonglorm Nipaporn
}

Department of Physical Therapy, Faculty of Associated Medical Sciences, Chiang Mai University, Thailand

To cite this article: Ariyachaikul S, Kanthain R, Thonglorm N. Reliability and validity of the Osteoarthritis Research Society International minimal core set of recommended performance-based tests of physical function in knee osteoarthritis in community-dwelling adults. Malays J Med Sci. 2020;27(2):77-89. https://doi.org/10.21315/mjms2020.27.2.9

To link to this article: https://doi.org/10.21315/mjms2020.27.2.9

\title{
Abstract
}

Background: The proper reliability analysis for specific type of data and limit study of various types of construct validity are crucial for performance-based tests for the knee osteoarthritis (OA) population. The purpose of this study was to evaluate relative and absolute reliability and construct validity of the Osteoarthritis Research Society International (OARSI) recommended minimal core set of performance-based tests in knee OA in community-dwelling adults.

Methods: Fifty-five primary knee OA (median age 69.0, interquartile range [IQR] 11.0) participated in the cross-sectional study. Three performance-based tests were performed in two sessions with a 1-week interval; 30-s chair stand test, 40-m fast-paced walk test and 9-step stair climb test. Relative reliability included intra-class correlation and Spearman's correlation coefficient (SPC). Absolute reliability included standard error of measurement, minimum detectable change, coefficient of variance, limit of agreement (LOA) and ratio LOA. Knee Injury and Osteoarthritis Outcome Score-Physical Function Short Form (KOOS-PS), knee extensor strength and pain scale were analysed for convergent validity using Pearson's correlation coefficient and SPC. Analysis of Covariance was utilised for known-groups validity.

Results: Relative and absolute reliability were all acceptable. LOA showed small systematic bias. Acceptable construct validity was only found with knee extensor strength. All tests demonstrated known-groups validity with medium to large effect size.

Conclusion: The OARSI minimum core set of performance-based tests demonstrated acceptable relative and absolute reliability and good known-groups validity but poor convergent validity.

Keywords: osteoarthritis, knee, performance-based test, physical function, outcomes, reliability, validity

\section{Introduction}

Knee osteoarthritis (OA) is the deteriorative risk to locomotive function and consequential frailty (1-2). Feasible and evidence-based measurement tools were needed for early detection and follow up of the disease state (3).
Assessment of physical function in knee $\mathrm{OA}$ is classified into self-reported and performancebased tests that conceptualised on the International Classification of Functioning, Disability and Health (ICF) (3-4). The minimal core set of three performance-based tests were recommended by the Osteoarthritis Research 
Society International (OARSI), which includes 30-s chair stand test (30sCST), 40-m fast-paced walk test (40mFPWT) and stair climb test (SCT) $(3,5)$. The 3 OsCST was preferred because of no floor effect in which poor physical function could complete the test (6). Forty-metre fastpaced walk test, a time-based, short-distance, untimed-turn and maximum walk speed, is a good test to evaluate performance response with environmental demand and is appropriate for lower extremity OA (7-8). Stair negotiation is one of the most difficult tasks to overcome. It is associated with the limit of function from sarcopenia, somatosensory and visual impairment and other disorders such as OA (9).

The assessment of psychometric property of the test is specific to clinical conditions and should cover various reliability (absolute and relative reliability) and construct validity (e.g. convergent, divergent and known-group) (4, 10-11). Two measurement property studies that targeted the OARSI recommended minimal core set of three performance-based tests in knee OA and knee arthroplasty (12-13). One of those studies showed acceptable relative reliability of all performance-based tests except 11-step SCT in which the outlier was removed before analysis (12). Moreover, in non-normal data of 11-step SCT (outlier not removed), minimum detectable change (MDC) was not calculated (12). It was contended that human performance measurement, which uses ratio scale, tended to be heteroscedastic (i.e. departure from normality; error related with measurement value) $(10,14)$. In this heteroscedastic type of data, the standard error of measurement (SEM) is a less effective representation of measurement error than the coefficient of variance (CV) and ratio limit of agreement (ratio LOA) (10, 15). So, the proper analysis for a specific type of data is much more concerned with reliability study. Another psychometric property study of the OARSI recommended minimal core set showed that three performance-based tests had a moderate correlation with quadriceps strength and low correlation with a self-reported test (Knee Injury and Osteoarthritis Outcome ScorePhysical Function Short Form [KOOS-PS]) and pain scale (13). Although this study provided a thorough convergent validity analysis, it did not investigate known-group validity. In a known-group study of 30sCST, the participants who ambulated with an assistive device were significantly different from the ones who did not (16). Therefore, the comparative study of the measurement property of comprehensive OARSI recommended minimal core set of performance-based tests were still needed (5). The purpose of this study was to evaluate the relative and absolute reliability and construct validity of the OARSI recommended minimal core set of performance-based tests in knee OA in community-dwelling adults.

\section{Methods}

\section{Population and Sampling}

This cross-sectional study of construct validity and reliability of three recommended performance tests for knee OA was performed in a sub-district community setting of Chiang Mai, a northern province of Thailand. The sample size for both construct validity and reliability was at least 50, as stated elsewhere (17). The study project was advertised via the community volunteer, the village head man and the Subdistrict Health Promoting Hospital (SHPH) personnel. The volunteers were screened by physical therapists and were included if they (i) met the American College of Rheumatology (ACR) clinical diagnostic criteria (with classification tree) for knee OA (18-19); (ii) were able to follow the instructions and could perform sit-to-stand, walk and climb the stairs and (iii) could read and fill out the questionnaire by themselves or with the help from their relatives who will read for them.

Subjects were excluded if they had a history of (i) rheumatoid and gouty arthritis or secondary OA; (ii) pain on the lower back and lower extremities other than the knees; (iii) injury/fracture with/without surgery on the lower back and lower extremities; (iv) congenital or acquired anomalies in the spine and lower extremities; (v) neurological problems; (vi) heart disease or high blood pressure not controlled by medication; (vii) intra-articular injection within 3 weeks; (viii) receiving alcohol or medications within $24 \mathrm{~h}$ that affect sleep or (ix) hearing and visual loss.

\section{Procedures}

Participants were appointed at the SHPH for the data collection on two sessions of performance-based testing, 1 week apart, to minimise recall effect and ensure real performance change (12). In session 1, participants performed three performance- 
based tests (30sCST, 40mFPWT and 9-step SCT) with three independent raters, i.e. each rater rated all participants by using only one test. All raters were physical therapists who had 7-12 years of clinical experience. The testing order of the tests for each participant was randomised to prevent a carry-over effect. A 5-min rest period between two consecutive measurements was allowed to ensure energy recruitment and fatigue prevention. Before testing, the physical therapist that was responsible for a specific test demonstrated the task, allowed the subjects to follow, gave feedback and stayed for safety prevention. In the first session, other than performance-based tests, the following data were collected: (i) baseline demographics; (ii) level of knee pain experienced over the past week assessed by an 11-point pain numerical rating scale (NRS) with $0=$ no pain and $10=$ worst pain (20); (iii) self-report difficulty to perform physical function assessed by the KOOS-PS and (iv) isometric knee extensor force measured with a hand-held dynamometer (HHD). In the second session, participants repeated three performance-based tests in the same order as they had done in the first session with the same raters. All raters were blind from the outcome of the first session. Half-day training for the test-specific therapists was taken before the data collection of the first week, including the following: questionnaire completion, NRS and KOOS-PS; set up, administration and recording of HHD and performance-based tests.

\section{Performance-Based Tests}

Measurement of the OARSI recommended minimal core set of performance-based tests (30sCST, 4OmFPWT and 9-step SCT) were strictly administered with the standard procedures provided in the OARSI website (https://www.oarsi.org/research/physical-

performance-measures). The 30sCST was performed on a chair, $43 \mathrm{~cm}$ in height, with straight backrest and without armrest. The 4OmFPWT was performed outdoors by walking straight at a distance of $10 \mathrm{~m}$ four times. Fast walking speed was calculated by excluding the turning time. The 9-step SCT was performed in the SHPH building on a 9-step (19 cm height/step) flight of stairs with handrail. The participants were allowed to use ambulation aids and/or handrail during the walking and stairclimbing tests.

\section{KOOS-PS}

KOOS-PS is a 7-item self-report on each individual's difficulty in performing daily functions. The 5-point Likert scale, which ranged from no difficulty to extreme difficulty, was rated. The scale was developed by using the Rasch analysis of multiple samples from many countries and extracted only seven most valid items (21). KOOS-PS showed good internal consistency (0.89) and good test-retest reliability (0.85-0.86) (22). Thai-version KOOS reported good internal consistency (0.9) and high test-retest reliability in ADL domains and moderate correlation to aggregated functional performance time (0.38 to 0.50 ) (23).

\section{Isometric Knee Extensor Torque}

The maximum voluntary isometric contraction was tested with Baseline ${ }^{\circledR}$ Hydraulic Hand Dynamometer (Fabrication Enterprise Inc., Elmsford, NY, USA). The dynamometer is liquid-hydraulic, $683 \mathrm{~g}$ in weight and is able to measure up to a maximum of $90 \mathrm{~kg}$. An adaptor was fixed with the distal leg just above the lateral malleolus (24). The participant sat upright on the table with the arms crossed and the hip and knee flexed at $90^{\circ}\left(0^{\circ}\right.$ as full knee extension) (24). Each participant performed two maximal contractions with a 5-min rest interval (25). During each contraction, the participant was instructed to gradually develop maximal strength over a few seconds and continue the maximal

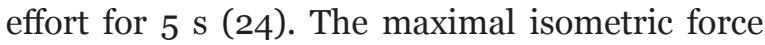
was converted into torque (Torque $[\mathrm{N} . \mathrm{m}]=$ Force $[\mathrm{kg}] \times$ leg length $[\mathrm{m}] \times 9.81[\mathrm{~m} / \mathrm{s} 2])(25)$. The torques of both legs were summed to aggregate knee extensor torques (AggKET), then divided by body mass to be aggregate knee extensor torques normalised by body mass (AggKETbm, N.m/kg) (26).

\section{Statistical Analysis}

The data analysis was performed with Statistical Package for Social Sciences (SPSS) version 17.0 (SPSS Inc., Chicago, IL, USA). The distribution of data was checked. If skewness or non-normality was identified, the natural logtransformation and back-transformation would be done (27-30). Geometric mean and 95\% confidence interval (CI) was estimated by Cox's modification (31-32). 


\section{Reliability Analysis}

Relative within-rater reliability was calculated using intra-class correlation coefficients $\left(\mathrm{ICC}_{2,1}\right)$ with $95 \% \mathrm{CI}$ for a two-way random effects model and absolute agreement (33). Lower one-sided 95\% CI $\mathrm{ICC}_{2,1}$ was also computed and $\geq 0.70$ was considered to be acceptable (12, 34). For non-normality data, Spearman's correlation coefficient (SPC), with 95\% CI and lower one-sided 95\% CI, were calculated using Fisher's transformation (35).

Absolute reliability included SEM, SEM percentage (SEM\%), MDC and LOA. SEM was calculated as the square root of mean square error, and 95\% CI was from sum square error and Chi-squared value from the $\mathrm{ICC}_{2,1}$ analysis of variance table (36). $\mathrm{MDC}_{90}$ was calculated from $1.65 \times \sqrt{ } 2 \times$ SEM. SEM\% was defined as $(\mathrm{SEM} /$ mean $) \times 100$ and $\mathrm{MDC}_{90}$ percentage $\left(\mathrm{MDC}_{90} \%\right)$ was $\left(\mathrm{MDC}_{90} /\right.$ mean $) \times 100$, when mean was the mean of all observations in both sessions 1 and 2 (37). A SEM\% of < 10\% was the acceptable random error regardless of measurement unit (38). Coefficient of variation percentage (CV\%) and 95\% CI were calculated with the root mean square method (39). CV\% < $10 \%$ was acceptable as the small difference lied within $10 \%$ of the mean (10). LOA was reported as LOA $=$ mean $_{\text {diff }} \pm 1.96(Z$-score of $95 \% \mathrm{CI}) \times$ $\mathrm{SD}_{\text {diff, }}$, when mean $_{\text {diff }}$ and $\mathrm{SD}_{\text {diff }}$ were the mean and SD of the difference between sessions (40). LOA should cover 'o' to show that there was a point where between-session scores were equal. LOA was separated into systematic bias (left component or mean difference) and random error (right component or SD component). The systematic bias was interpreted as a percentage of the grand mean of the sample (10). For nonnormality performance-based data, SEM (log scale), CV\% and ratio LOA were analysed. Ratio LOA $=\operatorname{mean}_{\text {Lndiff }}+1.96 \times \mathrm{SD}_{\text {Lndiff, }}$, when $\mathrm{Ln}_{\text {diff }}$ was the difference of the log-transformed session 1 and 2 scores $\left(\operatorname{Ln}_{\mathrm{s} 1}-\mathrm{Ln}_{\mathrm{s} 2}\right)(40)$. The logform of ratio LOA was later back-transformed (antilog $=\mathrm{e}^{\mathrm{s} 1 / \mathrm{s2}}$ ) and reported as antilog $\left(\operatorname{mean}_{\text {Lndiff }}\right) \mathrm{x} / \div \operatorname{antilog}\left(1.96 \times \mathrm{SD}_{\text {Lndiff }}\right)(14)$. Ratio LOA should cover ' 1 ', which indicated equal between-session scores. For ratio LOA, the bias was interpreted as the percentage between repeated mean.

\section{Validity Analysis}

The bivariate correlation coefficient was analysed among the performance-based test, KOOS-PS, normalised AggKET, NRS pain and age. Pearson's correlation coefficient (for normality data), SPC (for non-normality data and ordinal scale) and their 95\% CI was calculated using Fisher's transformation (35). For convergent validity, the relationship between performance test and the measurement with similar constructs (KOOS-PS, knee extension torque) should have a correlation coefficient at least moderate, $\geq 0.4$ or $\leq-0.4$ (13). All performance tests were evaluated for knowngroups validity using adaptation to stair climbing as an independent variable. The variable was categorised into two groups; non-adaptation and adaptation (e.g. use of walking aids or handrail). Subgroup comparison of each performance measure was done using $t$-test or univariate Analysis of Covariance (ANCOVA) if any covariates were detected. ANCOVA was perform with standard procedures and no violation of assumption; i.e. homogeneity of regression slope $\left(P\right.$-value for $\left.F_{\text {interaction }}>0.05\right)$, homogeneity of variance $(P$-value for Levene's test $>0.05)$ and variance ratio $\left(F_{\max } \geq 10: 1\right)(27,41)$. Main effect $F$-test, estimated marginal mean (statistical covariate adjustment), partial eta squared effect size $\left(\mathrm{Eta}^{2}\right)$ with $95 \%$ CI (non-centrality interval estimation) were calculated (41-43). Cohen's criteria for $\mathrm{Eta}^{2}$ was 0.01 (1\%) small effect, 0.06 (6\%) medium and 0.138 (14\%) large (41).

\section{Results}

Ninety-three community dwellers came to the village sites and screened using the ACR and eligibility criteria. Of those, 24 were excluded who did not meet ACR criteria ( $n$ $=7)$, had history of knee trauma $(n=4)$ and total knee replacement $(n=4)$, had knee pain related with spinal conditions $(n=2)$, other knee pathology, i.e. gout $(n=1)$ and rheumatoid arthritis $(n=2)$, were prone to fatigue and weak from coronary artery disease $(n=2)$, had chronic obstructive pulmonary disease $(n=1)$ and was unable to provide responses to personal medical history, pain scale and ACR questionnaire $(n=1)$. Of the remaining 69, 14 did not come after the screening session because of no transportation $(n=4)$, illness $(n=4)$, knee pain got worst $(n=2)$ and unknown 
( $n=4)$. Finally, 55 participants joined both sessions 1 and 2 of the data collection, and their complete data were available. The number of patients included and reasons for not being included in the study are summarised in Figure 1. Participant characteristics are presented in Table 1 . All variables were normally distributed, except SCT, age and body mass. Only 9-step SCT was natural log-transformed for further analysis. Their skewness and kurtosis were improved to be normal after transformation without the outlier.

\section{Between Sessions 1-Week Interval Within-Rater Reliability}

Descriptive data and within-rater absolute and relative reliability of three performancebased tests are presented in Table 2. In terms of relative reliability, all performance-based tests were well above acceptable levels (ICC and SPC $>0.85$, lower 1-sided 95\% CI > 0.7). Of all absolute reliability, SEM\% and MDC\% could be interpreted for normality data, i.e. 30sCST and 4OmFPWT. SEM\% of both tests was well under $10 \%(9.1 \%$ and $7.0 \%)$ of the mean test score and showed a small amount of random error. For CV\%, the 40mFPWT and 9-step SCT achieved an acceptable level of $<10 \%(6.9 \%$ and $6.7 \%$, respectively), whilst the 30sCST was $0.7 \%$ above the criteria (10.7\%). The LOA of both 30sCST and 40mFPWT showed small systematic bias ( -0.9 times and $-0.002 \mathrm{~m} / \mathrm{s}$, or $6.1 \%$ and $0.2 \%$ of the grand mean, respectively) and covered ' $\mathrm{o}$ ', meant that between sessions test scores were sometimes equal. The difference between session test scores of 30sCST and 40mFPWT, with 95\% CI, lied within 3.8 times and 0.245 $\mathrm{m} / \mathrm{s}$, respectively. For ratio LOA, the 9-step SCT

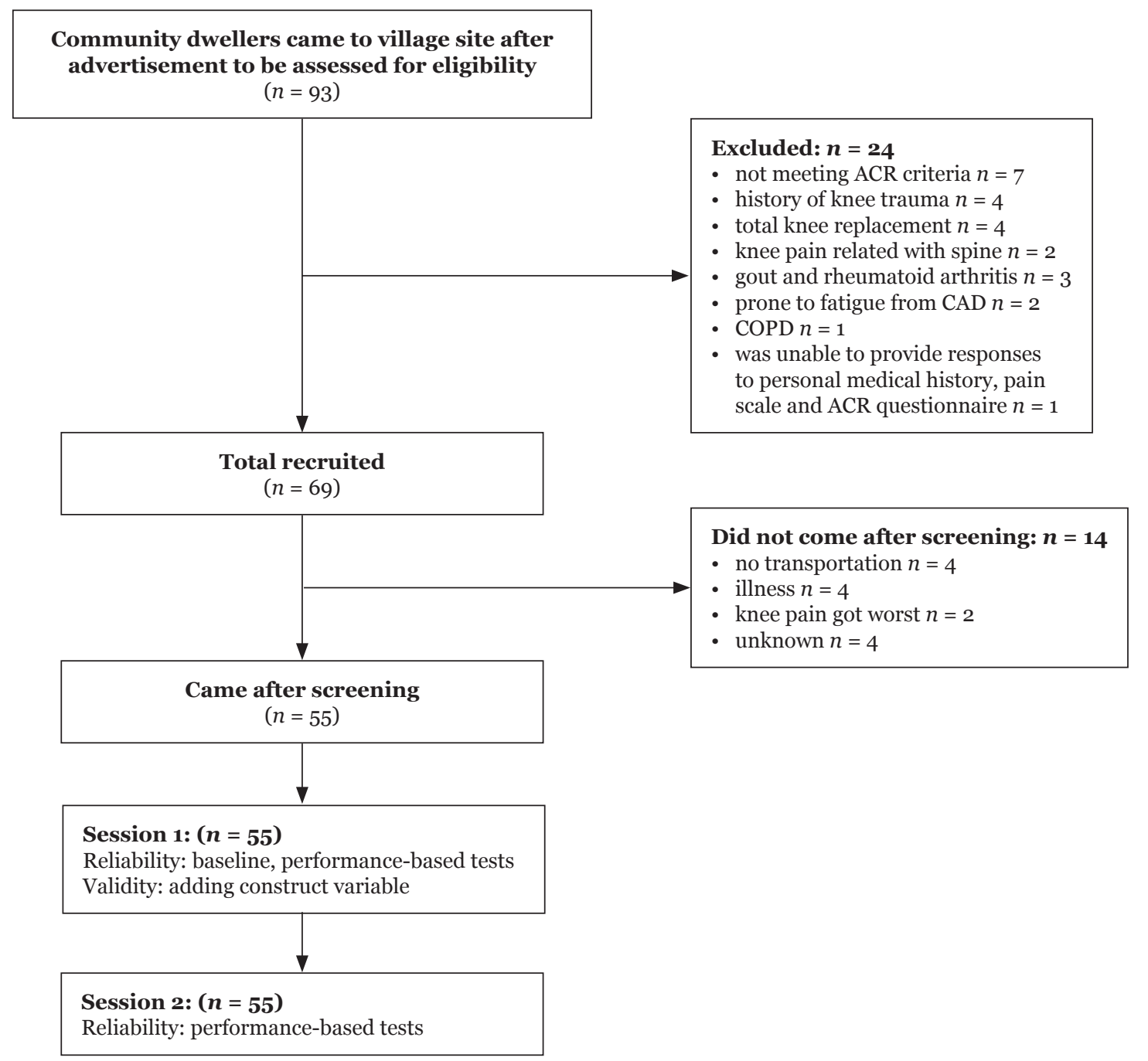

Figure 1. Number of patients excluded and included and reasons for not being included in the study 
Table 1. Baseline characteristics of the participants $(n=55)$

\begin{tabular}{lcc} 
Variables & Mean (SD) & $n(\%)$ \\
Age (years) & \\
Sex & $69.0(11)$ & $18(22.7)$ \\
$\quad$ Male & & $37(67.3)$ \\
$\quad$ Female & & \\
Height (m) & $1.54(0.09)$ & \\
Body mass (kg) & $50.0(15)$ & $10(18.2)$ \\
BMI groups & & $23(41.8)$ \\
$\quad$ Underweight (BMI < 18.50) & $5(9.1)$ \\
$\quad$ Healthy weight (BMI 18.50- 22.99) & $17(30.9)$ \\
$\quad$ Overweight (BMI 23.00-24.99) & & \\
Obese (BMI $\geq 25.00)$ & & $11(20.0)$ \\
OA side involved & & $11(20.0)$ \\
$\quad$ Unilateral (right) & & $33(60.0)$ \\
Unilateral (left) & & \\
Bilateral & & \\
NRS pain & & \\
KOOS-PS & & \\
AggKET (N.m) & & \\
AggKETbm (N.m/kg) & & \\
\hline
\end{tabular}

Note: $\mathrm{BMI}=$ body mass index; $\mathrm{SD}$ = standard deviation; $\mathrm{OA}=$ osteoarthritis; $\mathrm{NRS}$ = numerical rating scale; KOOS-PS = Knee Injury and Osteoarthritis Outcome Score-Physical Function Short Form; AggKET = aggregate knee extensor torque; AggKETbm = aggregate knee extensor torque; normalised by body mass; ${ }^{\mathrm{a}}$ median (interquartile range $=\mathrm{IQR}$ )

Table 2. Between sessions reliability and measurement errors $(n=55)$

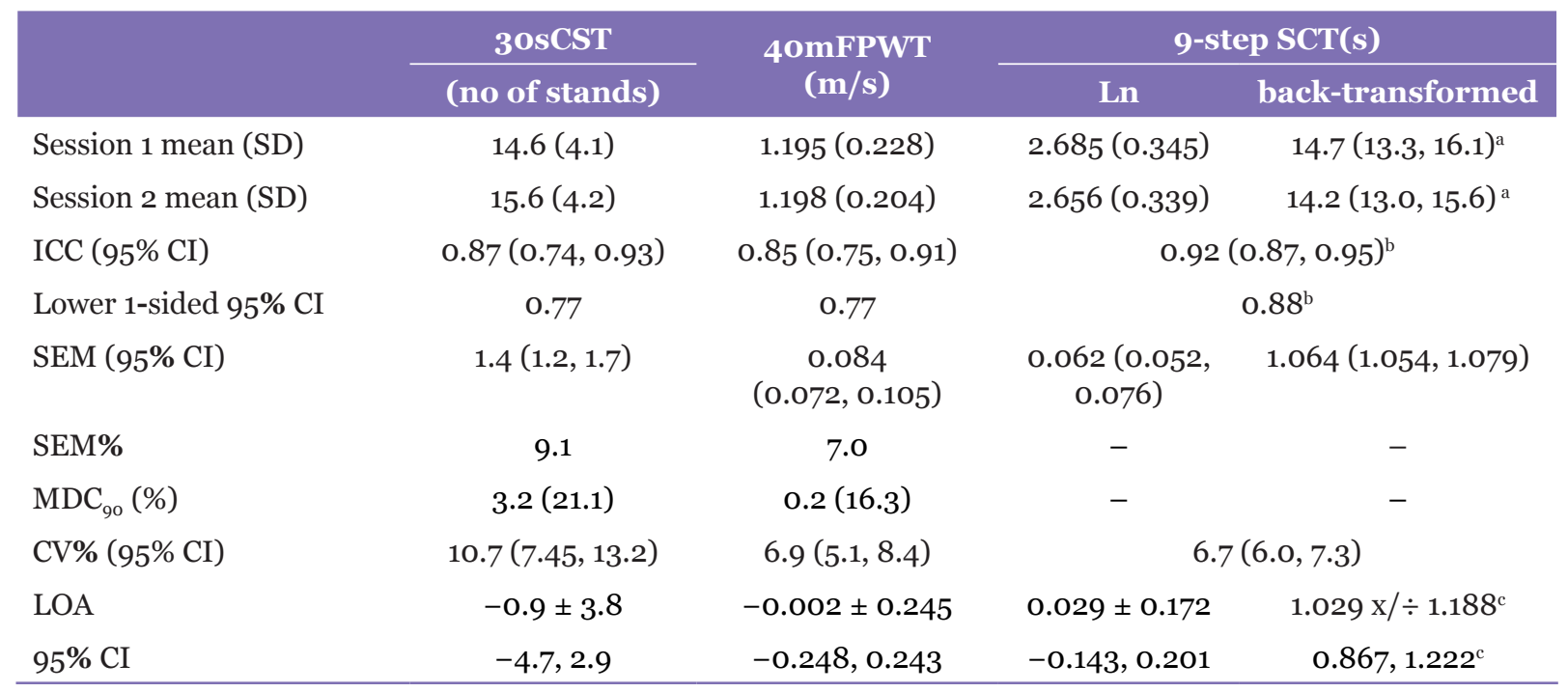

Notes: $30 \mathrm{OSCST}=$ 30-s chair-stand test; 40mFPWT = 40-m fast-paced walk test; 9-step SCT= 9-step stair climb test; Ln = natural $\log$ transformation; back-transformed $=$ antilog or exponent; $\mathrm{ICC}=$ intra-class correlation coefficient; $95 \% \mathrm{CI}=95 \%$ confidence interval; $\mathrm{SEM}=$ standard error of measurement; $\mathrm{MDC}_{90}=$ minimum detectable change at the $90 \% \mathrm{CI}$ level; $\mathrm{CV} \%=$ coefficient of variation percentage; LOA = limit of agreement; 'ageometric mean (95\% CI: lower limit, upper limit); 'bpearman's correlation coefficient; ' ratio LOA 
Original Article | Reliability validity performance tests knee OA

showed a ratio of 1.029 of systematic bias, which signified a $2.9 \%$ difference between session test scores, and a ratio of 1.188 of random error, which signified with $95 \%$ CI, no more than $18.8 \%$ of the difference.

\section{Construct Validity}

Bivariate correlation coefficients of the tested variables are shown in Table 3. Of three similar constructs, only AggKETbm met the minimum acceptable level of $\geq 0.4$ or $\leq-0.4$ with all performance-based tests ([30sCST, 0.41]; [40mFPWT, 0.50]; [9-step SCT, -0.42]). The KOOS-PS and KOOS-PS question 3 showed significant correlation only with 30sCST ( $r=-0.27$ and $r=-0.30$ ) but did not meet the minimum acceptable criteria. The 'absolute' correlation between KOOS-PS and NRS pain was higher than the correlation between all performance tests and NRS pain of at least 0.1 ([30sCST, 0.27/-0.05]; [40mFPWT, 0.27/-0.17]; [9-step SCT, 0.27/0.12]).

\section{Known-Groups Validity}

Since age was significantly $(P<0.01)$ related with all performance-based tests (30sCST, $r=-0.48$; 40mFPWT, $r=-0.37$; 9-step SCT, $r=-0.55$ ) ANCOVA adjusted for age was performed to compare the performance ability between non-adaptation and adaptation (during stair climbing) groups. The results of ANCOVA are presented in Table 4. All, except 9-step SCT model, showed no assumptions violation. Although the Levene's test demonstrated unequal variance, the $F_{\max }$ was less than 10:1, and near-equal sample size between cells ( $n=27$ and 28) supported robust ANCOVA analysis. With statistical age-adjustment, the

Table 3. Bivariate Pearson's correlation coefficient ( $95 \%$ CI) $(n=55)$

\begin{tabular}{|c|c|c|c|c|c|c|c|}
\hline & 30sCST & 40mFPWT & 9-step SCT ${ }^{a}$ & KOOS-PS & K-PS-Q3 ${ }^{\mathbf{a}}$ & $\mathbf{N R S}^{\mathbf{a}}$ & AggKETbm \\
\hline \multicolumn{8}{|l|}{ 30sCST } \\
\hline \multirow[t]{2}{*}{ 40mFPWT } & $0.57^{* *}$ & & & & & & \\
\hline & $\begin{array}{l}(0.35 \\
0.72)\end{array}$ & & & & & & \\
\hline \multirow[t]{2}{*}{ 9-step SCT } & $-0.60^{* *}$ & $-0.64^{* *}$ & & & & & \\
\hline & $\begin{array}{l}(-0.39 \\
-0.74)\end{array}$ & $\begin{array}{c}(-0.45 \\
-0.77)\end{array}$ & & & & & \\
\hline \multirow[t]{2}{*}{ KOOS-PS } & $-0.27^{*}$ & -0.22 & 0.23 & & & & \\
\hline & $\begin{array}{c}(-0.01 \\
-0.50)\end{array}$ & $\begin{array}{c}(-0.46 \\
0.05)\end{array}$ & $\begin{array}{c}(-0.04 \\
0.47)\end{array}$ & & & & \\
\hline \multirow[t]{2}{*}{ K-PS-Q3 ${ }^{\mathrm{a}}$} & $-0.30^{*}$ & -0.24 & 0.25 & $0.57^{* *}$ & & & \\
\hline & $\begin{array}{l}(-0.03 \\
-0.52)\end{array}$ & $\begin{array}{c}(-0.47 \\
0.03)\end{array}$ & $\begin{array}{c}(-0.02 \\
0.48)\end{array}$ & $\begin{array}{l}(0.35 \\
0.72)\end{array}$ & & & \\
\hline \multirow[t]{2}{*}{$\mathrm{NRS}^{\mathrm{a}}$} & -0.05 & -0.17 & 0.12 & $0.31^{*}$ & $0.34^{*}$ & & \\
\hline & $\begin{array}{c}(-0.31 \\
0.22)\end{array}$ & $\begin{array}{c}(-0.41 \\
0.10)\end{array}$ & $\begin{array}{c}(-0.15 \\
0.37)\end{array}$ & $\begin{array}{l}(0.04 \\
0.53)\end{array}$ & $\begin{array}{c}(0.08 \\
0.56)\end{array}$ & & \\
\hline \multirow[t]{2}{*}{ AggKETbm } & $0.41^{* *}$ & $0.50^{* *}$ & $-0.44^{* *}$ & $-0.28^{*}$ & $-0.29^{*}$ & 0.01 & \\
\hline & $\begin{array}{l}(0.16, \\
0.61)\end{array}$ & $\begin{array}{l}(0.28, \\
0.68)\end{array}$ & $\begin{array}{l}(-0.20 \\
-0.63)\end{array}$ & $\begin{array}{c}(-0.01 \\
-0.51)\end{array}$ & $\begin{array}{c}(-0.02 \\
-0.51)\end{array}$ & $\begin{array}{c}(-0.26 \\
0.28)\end{array}$ & \\
\hline \multirow[t]{2}{*}{$\operatorname{Age}^{a}$} & $-0.48^{* *}$ & $-0.37^{* *}$ & $0.55^{* *}$ & -0.06 & 0.09 & -0.01 & $-0.28^{*}$ \\
\hline & $\begin{array}{l}(-0.24 \\
-0.66)\end{array}$ & $\begin{array}{l}(-0.11 \\
-0.58)\end{array}$ & $\begin{array}{c}(0.34 \\
0.71)\end{array}$ & $\begin{array}{c}(-0.32 \\
0.21)\end{array}$ & $\begin{array}{c}(-0.18 \\
0.35)\end{array}$ & $\begin{array}{c}(-0.27 \\
0.26)\end{array}$ & $\begin{array}{l}(-0.01 \\
-0.50)\end{array}$ \\
\hline
\end{tabular}

Notes: ${ }^{* *}$ significant at $P<0.01,{ }^{*}$ significant at $P<0.05$

30sCST = 30-s chair-stand test; 4OMFPWT = 40-m fast-paced walk test; 9-step SCT = 9-step stair climb test; KOOS-PS = knee injury and osteoarthritis outcome score-physical function short form; K-PS-Q3 = KOOS-PS question no. 3 (rising from sitting);

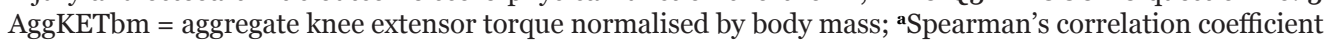


non-adaptation group had better performance than the adaptation group significantly with mean difference of 2.6 stands of 30 CST, $0.161 \mathrm{~m} / \mathrm{s}$ of $40 \mathrm{mFPWT}$ and $49.2 \%$ of 9 -step SCT. The percentage of variance in the DV (performance test scores), as explained by the IV (adaptation of 9-step SCT), was large in the 9-step SCT (40.6\%) and 40mFPWT (16.3\%) and medium in 30 CST (12.1\%).

\section{Discussion}

This study aimed to evaluate the psychometric properties of the OARSI recommended minimal core set of three performance-based tests, including various forms of reliability and construct validity. In terms of reliability, all tests showed acceptable levels of relative reliability and small measurement error. For convergent validity, the tests showed moderate correlation with age and knee extensor torque but low correlation or no relationship with self-reported physical function. In terms of known-group validity, all tests could discriminate between the use and non-use stairclimbing aids groups.
In terms of relative reliability, 9-step SCT showed better consistency than the other two tests. To compare the degree of absolute reliability from a different study, SEM\% is an accurate estimation for homoscedasticity and CV\% for heteroscedasticity. To determine whether the change of intervention is real, MDC\% is helpful for homoscedastic data. For heteroscedastic data, ratio LOA could be a minimum criterion of change $(10,14)$. In this study, the ratio of repeated 9-step SCT test time should be at least $18.8 \%$ (with $95 \% \mathrm{CI}$ ). The relative reliability (lower 1-sided ICC) of this study was within the same range as other studies $(12,44)$. However, the absolute reliability based on $\mathrm{MDC} 90 \%$, in this study (3OsCST, 21.1\%; 4OmFPWT, 16.3\%), showed little more error than those of previous study (3OSCST, 16.9\%; 4OmFPWT, 9.5\%). For 9-step SCT, MDC90\% of the previous study (18.8\% of the average mean) was comparable with the random error of ratio LOA in this study (18.8\% of the ratio betweensession mean). The mean 9-step SCT time of this study (14.2 s and $14.7 \mathrm{~s}$ ) was higher than that in a previous study (12) (13.27 s and 12.35 s). Age factor may conjunct the performance of this knee OA group and contribute to higher random error.

Table 4. Analysis of covariance on three performance-based tests (DV) adjusted for covariate $(n=55)$

\begin{tabular}{|c|c|c|c|c|c|c|c|}
\hline \multirow[b]{2}{*}{ DV } & \multicolumn{2}{|c|}{ Estimated mean (SE) } & \multirow{2}{*}{$\begin{array}{c}\text { Interaction } \\
\boldsymbol{F}_{1,51} \\
(P \text {-value })\end{array}$} & \multirow{2}{*}{$\begin{array}{c}\text { Levene } \\
F_{1,53} \\
(P \text {-value })\end{array}$} & \multirow[b]{2}{*}{$\operatorname{Var}_{R}$} & \multirow{2}{*}{$\begin{array}{c}\text { Main effect } \\
F_{1,52} \\
(P \text {-value })\end{array}$} & \multirow{2}{*}{$\begin{array}{c}\mathrm{Eta}^{2} \\
(95 \% \mathrm{CI})^{2}\end{array}$} \\
\hline & $\begin{array}{c}\text { Ad. } \\
(n=27)\end{array}$ & $\begin{array}{l}\text { Non-Ad. } \\
(n=\mathbf{2 8})\end{array}$ & & & & & \\
\hline 30sCST & $\begin{array}{c}13.30 \\
(0.670)\end{array}$ & $\begin{array}{c}15.89 \\
(0.657)\end{array}$ & 0.119 & 0.610 & 1.066 & 7.139 & 0.121 \\
\hline (no. of stands) & & & $(0.732)$ & (0.438) & & (0.010) & $\begin{array}{c}(0.007 \\
0.289)\end{array}$ \\
\hline 40mFPWT & $\begin{array}{c}1.12 \\
(0.035)\end{array}$ & $\begin{array}{c}1.28 \\
(0.034)\end{array}$ & 0.070 & 1.924 & 1.413 & 10.159 & 0.163 \\
\hline$(\mathrm{m} / \mathrm{s})$ & & & $(0.792)$ & $(0.171)$ & & $(0.002)$ & $\begin{array}{c}(0.023, \\
0.336)\end{array}$ \\
\hline 9-step SCT ${ }^{\mathrm{b}}$ & $\begin{array}{c}2.80 \\
(0.046)\end{array}$ & $\begin{array}{c}2.40 \\
(0.046)\end{array}$ & 0.024 & 15.666 & 3.565 & 35.548 & 0.406 \\
\hline (s) & & & $(0.877)$ & $(<0.001)$ & & $(<0.001)$ & $\begin{array}{c}(0.200 \\
0.555)\end{array}$ \\
\hline
\end{tabular}

Notes: DV = dependent variable; estimated mean (SE) = estimated marginal mean and standard error of the mean by covariate (age) adjustment at 71.20 years; Ad. = stair climb with adaptation; Non-Ad. = stair climb without adaptations; interaction = test of homogeneity of regression or interaction between covariate (age) and independent variable (Ad./Non-Ad.); Levene = Levene's test of homogeneity of variance; $\operatorname{Var}_{\mathrm{R}}=$ variance ratio or $\mathrm{F}_{\text {max }}$; main effect = univariate ANCOVA between effect; $\mathrm{Eta}^{2}$ = partial eta squared or effect size; 30sCST = 30-s chair-stand test; 40mFPWT = 40m fast-paced walk test; $\mathrm{SCT}=9$-step stair climb test;

${ }^{\mathrm{a} N o n}$ centrality interval estimation, ${ }^{\mathrm{b}} \mathrm{Natural} \log$ transformation 
For convergent validity, AggKETbm was the only construct that passed the minimum acceptable criteria. The self-report physical function (KOOS-PS) did not show significant correlation with all the performance-based tests except 30sCST. However, the KOOS-PS and 30sCST correlation coefficient were less than the criteria. The 'absolute' correlation between KOOS-PS and NRS pain was higher than the correlation between all performance tests and NRS pain. Since self-report and performancebased tests were developed to assess similar function in OA (3) (e.g. ICF conceptualisation), it was expected to have a meaningful association. The result of this study and the previous study did not respect this premise. These unmet criteria of the correlation might give the idea of the content validity of both self-reported and performance-based tests. Timed measurement of task performance is the reduction of direct observation to be one quantifiable dimension, which dismisses erroneous movement (i.e. impairment) (45-46). It was advocated that the assessed content of the self-report was not only the patient's ability to move around but also the patient's subjective response to accumulated past experiences (i.e. pain and perceived exertion) (45). The results in the influence of pain on the self-report were more than the pain experienced upon the execution of that task $(13,45,47)$, as showed in this study.

In this study, the failure of the three performance-based tests to show hypothesised relationship with KOOS-PS and NRS might be the problem of construct under representation (48). If a measured test underrepresents the physical component function, it fails to capture the important aspects of the construct it purports to measure. In this study, the correlation between 30sCST and K-PS-Q3 or the question number 3 was more than the correlation with KOOS-PS, which also suggested that 30 OSCST was more strongly represented by a component of KOOS-PS.

For known-group validity, this study used stair climbing aids (use/non-use) as a discriminatory factor, which was differed from the previous study (gait aid/no gait aid) (16). Since age was correlated well with all performance-based tests and also showed a significant difference between use and non-use stair climbing aids (not presented in the results; independent $t$-test $=-2.763, P=0.008$ ), the age was adjusted to accurately estimate the effect size. All three performance-based tests demonstrated evidence of known-groups validity by differentiation of the knee OA group with aids from the group without aids. The 9-step SCT showed a larger effect size than the other two tests. It suggested that 9-step SCT was more relevant to adaptation of stair climbing factor than 3 OSCST and 4OmFPWT.

In this study, heterogeneity of data and skewness were observed in the stair-climbing performance test. Natural log was used to transform because of easy-interpretation when back-transformation as stated above. The Cox estimation of $95 \%$ CI was selected because of its smallest coverage error for a medium sample size (31). With our knowledge, this is the first study to estimate various absolute reliability of recommended performancebased tests, specifically for different data types (e.g. homogenous and heterogeneous). Since some human performance measurement was recorded in a ratio scale and lead to heteroscedastic errors (14), the CV\% and ratio LOA were more appropriate. A 1-week duration was set to ensure between-session within-rater reliability rather than test-retest reliability, as other studies $(13,49)$. The sources of heteroscedasticity in 9-step SCT seemed to relate with the level of adaptation whose division made a large effect size. Age factor was the confounder for construct validity of these performancebased tests. According to the Thailand context of knee OA burden in community-dwelling elderly (22.5\% in 2014) (50), the combined effects of sarcopenia and arthrogenically reduced voluntary activation mechanism to strength and function deterioration which should be considered $(2,51-53)$.

This study had several limitations. First, the study design was cross-sectional and scope on the change of repeated measurement rather than responsiveness of the change from intervention. Second, although the proposed sample size of $>50$ is adequate (17), the heteroscedastic data might need more sample size than 'adequate'. Third, KOOS-PS had narrow valid content. It showed an inferior ability to assess lower extremity function than KOOS functional and Sports items sum scores (54). The reduction of items might result in the under representation of KOOS-PS. Lastly, the measures used for convergent validation might well selected on other relevant outcomes such as quality of life, pain associated with function. 


\section{Conclusion}

This study evaluated a number of selected psychometric properties of the OARSI recommended minimal core set of performancebased tests in knee OA. The reliability and measurement error estimated all tests to meet the acceptable criteria. MDC9o and random error component of ratio LOA were calculated for useful decision of real change. The convergent validity only with knee extensor strength demonstrated limited representation. The performance-based tests had medium to large effect size in discriminating the group adaptation to stair climbing. The study suggested using specific calculation of absolute reliability to homo-/heterogenic data.

\section{Acknowledgements}

We would like to express our gratitude to the heads and the officials of SHPH in Mae Rim, Chiang Mai province for assistant and support during conducting the research.

\section{Ethics of Study}

The ethical clearance of the study was approved by the human ethic committee of the institution (study code AMSEC-59EX-003).

\section{Conflict of Interest}

None.

\section{Funds}

\section{None.}

\section{Authors' Contributions}

Conception and design: AS

Analysis and interpretation of the data: AS

Drafting of the article: AS

Critical revision of the article for important

intellectual content: AS

Final approval of the article: AS

Provision of study materials or patients: KR, TN

Statistical expertise: AS

Obtaining of funding: AS, KR, TN

Administrative, technical, or logistic support: KR

Collection and assembly of data: TN

\section{Correspondence}

Dr Ariyachaikul Suwit

Assistant Professor

BScPT (Mahidol University), PGDipSpPhty

(Curtin Univerisity of Technology), MSc in

Health Development (Chulalongkorn University)

Department of Physical Therapy,

Faculty of Associated Medical Sciences,

Chiang Mai University,

110 Intawaroros Rd, Sripoom,

50200 Chiang Mai, Thailand.

Tel: +6653935063

Fax: +6653936042

E-mail: sao7ams@gmail.com

\section{References}

1. Ishijima $M$, Kaneko $H$, Hada S, Kinoshita $M$, Sadatsuki R, Liu L, et al. Osteoarthritis as a cause of locomotive syndrome: Its influence on functional mobility and activities of daily living. Clin Rev Bone Miner Metab. 2016;14(2):77-104. https://doi.org/10.1007/s12018-016-9212-6

2. Culvenor AG, Ruhdorfer A, Juhl C, Eckstein F, Øiestad BE. Knee extensor strength and risk of structural, symptomatic, and functional decline in knee osteoarthritis: A systematic review and meta-analysis. Arthritis Care Res. 2017;69(5):649-658. http://doi.org/10.1002/ acr.23005

3. Dobson F, Hinman RS, Roos EM, Abbott JH, Stratford P, Davis AM, et al. OARSI recommended performance-based tests to assess physical function in people diagnosed with hip or knee osteoarthritis. Osteoarthritis Cartilage. 2013;21(8):1042-1052. http://doi.org/10.1016/j. joca.2013.05.002

4. Finch E, Brooks D, Stratford PW, Mayo NE. Physical rehabilitation outcome measures: a guide to enhanced clinical decision making. Ontario: Canadian Physiotherapy Association; 2002.

5. Dobson F, Hinman RS, Hall M, Terwee CB, Roos EM, Bennell KL. Measurement properties of performance-based measures to assess physical function in hip and knee osteoarthritis: a systematic review. Osteoarthritis Cartilage. 2012;2o(12):1548-1562. http://doi. org/10.1016/j.joca.2012.08.015 
6. Jones CJ, Rikli RE, Beam WC. A 30-s chairstand test as a measure of lower body strength in community-residing older adults. Res $Q$ Exerc Sport. 1999;70(2):113-119. http://doi.org/10.108 o/02701367.1999.10608028

7. Bennell K, Dobson F, Hinman R. Measures of physical performance assessments: self-paced walk test (SPWT), stair climb test (SCT), sixminute walk test (6MWT), chair stand test (CST), timed up \& go (TUG), sock test, lift and carry test (LCT), and car task. Arthritis Care Res. 2011;63(S11):S350-S370. http://doi.org/ 10.1002/acr.20538

8. Middleton A, Fritz SL, Lusardi M. Walking speed: The functional vital sign. $J$ Aging Phys Act. 2015;23(2):314-322. http://doi.org/10.1123/ japa.2013-0236

9. Nightingale EJ, Pourkazemi F, Hiller CE. Systematic review of timed stair tests. $J$ Rehabil Res Dev. 2014;51(3):335-350. http://doi. org/10.1682/jrrd.2013.06.0148

10. Atkinson G, Nevill AM. Statistical methods for assessing measurement error (reliability) in variables relevant to sports medicine. Sports Med. 1998;26(4):217-238. http://doi. org/10.2165/00007256-199826040-00002

11. Nunnally JC, Bernstein IH. Psychometric theory. 3rd ed. New York: McGraw-Hill; 1994.

12. Dobson F, Hinman RS, Hall M, Marshall CJ, Sayer T, Anderson C, et al. Reliability and measurement error of the Osteoarthritis Research Society International (OARSI) recommended performance-based tests of physical function in people with hip and knee osteoarthritis. Osteoarthritis Cartilage. 2017;25(11):1792-1796. http://doi.org/10.1016/j.joca.2017.06.006

13. Tolk JJ, Janssen RPA, Prinsen CAC, Latijnhouwers DAJM, van der Steen MC, Bierma-Zeinstra SMA, et al. The OARSI core set of performance-based measures for knee osteoarthritis is reliable but not valid and responsive. Knee Surg Sports Traumatol Arthrosc. 2019;27:2898-2909. http://doi. org/10.1007/so0167-017-4789-y

14. Nevill A, Atkinson G. Assessing agreement between measurements recorded on a ratio scale in sports medicine and sports science. Br J Sports Med. 1997;31:314-318. http://doi.org/10.1136/ bjsm.31.4.314
15. Hopkins WG. Measures of reliability in sports medicine and science. Sports Med. 2000;30(1):1-15. http://doi. org/10.2165/00007256-200030010-00001

16. Gill SD, Morton NAD, Burney HM. An investigation of the validity of six measures of physical function in people awaiting joint replacement surgery of the hip or knee. Clin Rehabil. 2012;26(10):945-951. http://doi. org/10.1177/0269215511434993

17. Terwee CB, Bot SDM, de Boer MR, van der Windt DAWM, Knol DL, Dekker J, et al. Quality criteria were proposed for measurement properties of health status questionnaires. $J$ Clin Epidemiol. 2007;60(1):34-42. http://doi.org/10.1016/j. jclinepi.2006.03.012

18. Altman R, Asch E, Bloch D, Bole G, Borenstein $\mathrm{D}$, Brandt K, et al. Development of criteria for the classification and reporting of osteoarthritis: Classification of osteoarthritis of the knee. Arthritis Rheum. 1986;29(8):1039-1049. http://doi.org/10.1002/art.1780290816

19. Altman RD. Criteria for the classification of osteoarthritis of the knee and hip. Scand $J$ Rheumatol. 1987;16(Suppl):31-39. http://doi. org/10.3109/03009748709102175

20. Hawker GA, Mian S, Kendzerska T, French M. Measures of adult pain: visual analog scale for pain (VAS Pain), numeric rating scale for pain (NRS Pain), McGill pain questionnaire (MPQ), short-form McGill pain questionnaire (SF-MPQ), chronic pain grade scale (CPGS), short form-36 bodily pain scale (SF-36 BPS), and measure of intermittent and constant osteoarthritis pain (ICOAP). Arthritis Care Res. 2011;63(S11):S240-S252. http://doi. org/10.1002/acr.20543

21. Perruccio AV, Stefan Lohmander L, Canizares M, Tennant A, Hawker GA, Conaghan PG, et al. The development of a short measure of physical function for knee OA KOOS-physical function shortform (KOOS-PS)-an OARSI/ OMERACT initiative. Osteoarthritis Cartilage. 2008;16(5):542-550. http://doi.org/10.1016/j. joca.2007.12.014 
22. Collins NJ, Misra D, Felson DT, Crossley KM, Roos EM. Measures of knee function: International Knee Documentation Committee (IKDC), subjective knee evaluation form, knee injury and osteoarthritis outcome score (KOOS), knee injury and osteoarthritis outcome score physical function short form (KOOS-PS), knee outcome survey activities of daily living scale (KOS-ADL), Lysholm knee scoring scale, Oxford knee score (OKS), Western Ontario and McMaster Universities Osteoarthritis index (WOMAC), activity rating scale (ARS), and Tegner activity score (TAS). Arthritis Care Res. 2011;63(S11):S208-S228. http://doi. org/10.1002/acr.20632

23. Chaipinyo K. Test-retest reliability and construct validity of the Thai version of knee osteoarthritis outcome scores (KOOS). Thai $J$ Phys Ther. 2009;31(2):67-76.

24. Bohannon R. Measuring knee extensor muscle strength. Am J Phys Med Rehabil. 2001;80:1318. http://doi.org/10.1097/00002060200101000-00004

25. Clements S, Samuel D. Knee extensor strength measured using a Biodex dynamometer and an adapted hand held dynamometer. Int $J$ Ther Rehabil. 2014;21(6):274-278. http://doi. org/10.12968/ijtr.2014.21.6.274

26. Jaric S, Mirkov D, Markovic G. Normalizing physical performance tests for body size: a proposal for standardization. $J$ Strength Cond Res. 2005;19(2):467-474. http://doi. org/10.1519/r-15064.1

27. Tabachnick BG, Fidell LS. Using multivariate statistics. 5th ed. Boston: Pearson Education; 2007.

28. Bland JM, Altman DG. Statistics notes: transformations, means, and confidence intervals. BMJ. 1996;312(7038):1079. http://doi. org/10.1136/bmj.312.7038.1079

29. Bland JM, Altman DG. Statistics notes: the use of transformation when comparing two means. BMJ. 1996;312(7039):1153. http://doi.org/10.1136/ bmj.312.7039.1153

30. Cole TJ, Altman DG. Statistics notes: Percentage differences, symmetry, and natural logarithms. BMJ. 2017;358:j3683. http://doi.org/10.1136/ bmj.j3683
31. Zhou X-H, Gao S. Confidence intervals for the log-normal mean. Stat Med. 1997;16(7):783-790. http://doi.org/10.1002/ (SICI)1097-0258(19970415)16:7<783::AIDSIM488>3.0.CO;2-2

32. Olsson U. Confidence intervals for the mean of a log-normal distribution. $J$ Stat Educ. 2005;13(1):1-9. http://doi.org/10.1080/1069189 8.2005.11910638

33. Koo TK, Li MY. A guideline of selecting and reporting intraclass correlation coefficients for reliability research. $J$ Chiropr Med. 2016;15(2):155-163. http://doi.org/10.1016/j. jcm.2016.02.012

34. Prinsen CAC, Vohra S, Rose MR, Boers M, Tugwell P, Clarke M, et al. How to select outcome measurement instruments for outcomes included in a "Core Outcome Set" - a practical guideline. Trials. 2016;17(1):449. http://doi.org/10.1186/ s13063-016-1555-2

35. Bishara AJ, Hittner JB. Confidence intervals for correlations when data are not normal. Behav Res Methods. 2017;49(1):294-309. http://doi. org/10.3758/s13428-016-0702-8

36. Stratford PW, Goldsmith CH. Use of the standard error as a reliability index of interest: an applied example using elbow flexor strength data. Phys Ther. 1997;77(7):745-750. http://doi. org/10.1093/ptj/77.7.745

37. Wagner JM, Rhodes JA, Patten C. Reproducibility and minimal detectable change of threedimensional kinematic analysis of reaching tasks in people with hemiparesis after stroke. Phys Ther. 2008;88(5):652-663. http://doi. org/10.2522/ptj.20070255

38. Goldberg A, Casby A, Wasielewski M. Minimum detectable change for single-leg-stance-time in older adults. Gait Posture. 2011;33(4):737739. http://doi.org/https://doi.org/10.1016/j. gaitpost.2011.02.020

39. Bland M. How should I calculate a withinsubject coefficient of variation? [Internet]. York: University of York; 2006 [updated 2006 Oct 16; Retrieved 2019 May 20]. Available at: https:// www-users.york.ac.uk/ mb55/meas/cv.htm 
Original Article | Reliability validity performance tests knee OA

40. Bland MJ, Altman DG. Statistical methods for assessing agreement between two methods of clinical measurement. Lancet. 1986;327(8476):307-310. http://doi. org/10.1016/So140-6736(86)90837-8

41. Pallant J. SPSS survival manual: A step by step guide to data analysis using SPSS for Windows. 3rd ed. Bergshire: Open University Press/ McGraw-Hill; 2007.

42. Wuensch KL. Standardized effect size estimation: why and how? [Internet]. Greenville: East Carolina University; 2015 [Retrieved 2019 May 27]. Available at: http://core.ecu.edu/ psyc/wuenschk/StatHelp/Effect\%20Size\%20 Estimation.pdf

43. Wuensch KL. Construct confidence interval for $\mathrm{R}^{2}$ from regression analysis, SPSS syntax [Internet]. Greenville: East Carolina University; 2016 [Retrieved 2019 May 27]. Available at: http:// core.ecu.edu/psyc/wuenschk/SPSS/CI-R2-SPSS. zip

44. Kennedy DM, Stratford PW, Wessel J, Gollish JD, Penney D. Assessing stability and change of four performance measures: a longitudinal study evaluating outcome following total hip and knee arthroplasty. BMC Musculoskelet Disord. 2005;6(1):3. http://doi.org/10.1186/1471-24746-3

45. Stratford PW, Kennedy DM. Performance measures were necessary to obtain a complete picture of osteoarthritic patients. $J$ Clin Epidemiol. 2006;59(2):160-167. http://doi. org/10.1016/j.jclinepi.2005.07.012

46. Steultjens MPM, Dekker J, van Baar ME, Oostendorp RAB, Bijlsma JWJ. Internal consistency and validity of an observational method for assessing disability in mobility in patients with osteoarthritis. Arthritis Care Res. 1999;12(1):19-25. http://doi.org/10.1002/15290131(199902)12:1<19::Aid-art4>3.0.Co;2-v
47. Terwee CB, van der Slikke RMA, van Lummel RC, Benink RJ, Meijers WGH, de Vet HCW. Self-reported physical functioning was more influenced by pain than performance-based physical functioning in knee-osteoarthritis patients. J Clin Epidemiol. 2006;59(7):724-731. http://doi.org/10.1016/j.jclinepi.2005.11.019

48. Piva SR, Fitzgerald GK, Irrgang JJ, Bouzubar F, Starz TW. Get up and go test in patients with knee osteoarthritis. Arch Phys Med Rehabil. 2004;85(2):284-289. http://doi.org/10.1016/j. apmr.2003.05.001

49. Gill S, McBurney H. Reliability of performancebased measures in people awaiting joint replacement surgery of the hip or knee. Physiother Res Int. 2008;13(3):141-152. http:// doi.org/10.1002/pri.411

50. Aekplakorn W. Thai National Health Examination Survey, NHES V 2014 [Internet]. Nonthaburi (TH): Health System Research Institute (HRSI); 2017 Mar [Retrieved 2019 May 20]. Available at: http://thaitgri.org/?p=37869 Thai

51. Hurley MV. Quadriceps weakness in osteoarthritis. Curr Opin Rheumatol. 1998;10:246-250. http://doi. org/10.1097/00002281-199805000-00015

52. Schwartz RS. Sarcopenia and physical performance in old age: introduction. Muscle Nerve. 1997;20(S5):10-12. http://doi. org/10.1002/(SICI)1097-4598(1997)5+<10::AIDMUS3>3.0.CO;2-M

53. Doherty TJ. The influence of aging and sex on skeletal muscle mass and strength. Curr Opin Clin Nutr Metab Care. 2001;4(6):503-508. http:// doi.org/10.1097/00075197-200111000-00007

54. Stratford PW, Kennedy DM. A comparison study of KOOS-PS and KOOS function and sport scores. Phys Ther. 2014;94(11):1614-1621. http://doi. org/10.2522/ptj.20140086 